\title{
Comparative Study between 3D Balanced Fast Field Echo Sequence and 3D Driven Equilibrium Sequence in the Assessment of the Inner Ear Structure and Internal Auditory Canal Nerves
}

\author{
AHMED S. ABDELRAHMAN, M.D.; ALIAA S. SHEHA, M.D. and MENA E.Y. EKLADIOUS, M.D. \\ The Department of Radiology, Faculty of Medicine, Ain Shams University
}

\begin{abstract}
Background: MR cisternography using three dimensional (3D) heavily T2-weighted imaging techniques is considered the main imaging modality for identification and assessment of inner ear structures anatomy and pathology as well as for identification of the posterior fossa cranial nerves, and there are two techniques that are usually used which are fast spinecho including Driven equilibrium (DRIVE) and fast gradientecho techniques including Balanced fast field echo (bFFE).
\end{abstract}

Aim of Study: To compare the image quality of 3D DRIVE and $3 \mathrm{D}$ bFFE sequences in the assessment of the inner ear structures and internal auditory canal cranial nerves.

Material and Methods : 15 patients underwent MR imaging of the temporal bone using both 3D bFFE and 3D DRIVE sequences with a comparison between the two sequences as regards the clarity of cranial nerves and inner ear structures.

Results: The 3D bFFE sequence was statistically significantly better than 3D DRIVE for demonstration of the cochlear, and vestibular nerves, and it was slightly better for visualizing the facial nerve as well as the cochlear inner structure. The 3D DRIVE showed a statically insignificant supremacy over 3D bFFE for visualization of the three semicircular canals and vestibule.

Conclusion: The 3D bFFE shows slightly better imaging quality over 3D DRIVE with the advantage of less imaging time.

Key Words: $M R I-3 D$ bFFE $-3 D$ DRIVE $-I A C$.

\section{Introduction}

MR cisternography using three dimensional (3D) heavily T2-weighted imaging techniques is considered the main imaging modality for identification and assessment of inner ear structures anatomy and pathology as well as for identification of the posterior fossa cranial nerves especially the internal

Correspondence to: Dr. Ahmed S. Abdelrahman, E-Mail:dr ahmedsamy@yahoo.com auditory canal (IAC) cranial nerves [1-5], so it is considered the modality of choice in preoperative assessment before cochlear implant surgery, giving proper anatomical and pathological information about the integrity of the cochlear nerve and the cochlea which is mandatory before surgery [6] .

Basically, two techniques denoted by various names are most widely used to provide high spatial resolution MR imaging of the petrous bone: Fast spin-echo (FSE) and fast gradient-echo techniques (FGRE) [7,8]. Both of them can be performed either as 2 dimensions (2D) or 3 dimensions (3D), yet the $3 \mathrm{D}$ technique provide volume imaging with ultra-thin slices and reformatted images can be performed from them [9].

Driven equilibrium (DRIVE), is a fast recovery fast spin-echo sequence (FRFSE) that apply a group of additional 90 recovery pulses at the end of echo train to increase the speed of relaxation and reversion of the remaining transverse magnetization back to the longitudinal axis [10]. Balanced fast field-echo (bFFE) is an FGRE sequence that uses a balanced gradient waveform for all gradient directions to guarantee high signal for tissues with a high $\mathrm{T} 2 / \mathrm{T} 1$ ratio [11].

The aim of this study was to assess the difference in the image quality of $3 \mathrm{D} \mathrm{bFFE}$ and $3 \mathrm{D}$ DRIVE sequences for discrimination of the internal auditory canal cranial nerves and inner ear structures.

\section{Material and Methods}

\section{Patients:}

This prospective study included fifteen patients with examination of thirty inner ear; (five men and 
ten women), referred to the radiology department, El-Demerdash Hospital form Outpatient Clinic and other Hospital Departments to obtain brain MR imaging for various reasons during the period from September 2018 till February 2019, the patients mean age was 20 years (range from 6 months to 40 years). An informed consent was obtained from all patients participated in this study according to the rules of ethical committee.

\section{Inclusion criteria:}

1- Male or female patient underwent MRI examination with no age resection.

\section{Exclusion criteria:}

1- Past medical history or clinical signs \& symptoms related to ear diseases.

2- Any patient showing significant abnormality in his/her brain MR image.

3- Contraindications to MRI.

Study tools:

All patients underwent the MRI on 1.5 T Philips Achieva scanner MRI system using a 16-channel sensitivity-encoding head coil and after completion of routine unenhanced MR imaging of the brain, 3D imaging of temporal bone region using both 3D DRIVE and 3D bFFE sequences were performed in the axial plane parallel to the orbitomeatal line, with slick thickness $=1.4 \mathrm{~mm}$ and slice spacing $=0.7 \mathrm{~mm}$.

The MRI parameters of $3 D$ DRIVE and $3 D$ bFFE were as follow:

The imaging parameters for 3D DRIVE were: TR/TE (1500ms/250ms), 90 flip angle, 256 x 204 matrix, $15 \times 15 \mathrm{~cm}$ field of view, with SENSE factor of 2 , the acquisition time was 5 minutes 12 seconds.

The imaging parameters used for $3 \mathrm{D} \mathrm{bFFE}$ were: TR/TE (9.4ms/4.7ms), 50 flip angle, $256 \mathrm{x}$ 192 matrix, and $15 \times 15 \mathrm{~cm}$ field of view, the acquisition time was 2 minutes 45 seconds.

\section{Data interpretation:}

The images were then reviewed by 2 head and neck radiologists with specific points to comment on the clarity of facial, cochlear, superior and inferior vestibular nerves, as well the visualization of the cochlear turns (basal, middle and apical), the modiolus, vestibule, superior, inferior and lateral semicircular canals. Measurement of the diameter of the basal turn of the cochlea was also included.

The radiologists were asked to grade the visibility of the inner ear structures, facial and vestib- ulocochlear nerves as good and fair with good to represent clear visualization with high grade of contrast resolution, and fair as poor contrast resolution with ambiguity in separating the investigated structure borders from the surrounding CSF, when there was difference between the two radiologists a final decision was made by consensus. Then the results of both 3D DRIVE and 3D bFFE were compared.

Statistical analysis: The data analysis was performed using computer programs SPSS (version 15 for Microsoft Windows). The chi-square test was performed for the cranial nerves within the IAC, the cochlear middle and apical turns, and the modiolus of the cochlea, and the paired $t$-test was used for the cochlear basal turn. A $p$-value of less than 0.05 was considered statistically significant.

\section{Results}

Fifteen patients have participated in this study with a total assessment of thirty IAC and inner ear structures, the patient's age range was from 6 months to 40 years, with a mean age of 20 years.

The difference in the image quality for demonstration of the inner ear structures and cranial nerves within the IAC using 3D bFFE and 3D DRIVE was summarized in Tables $(1,2,3)$. Pulsation artifacts were noted in some cases in the 3D DRIVE sequences that hindered proper assessment of cranial nerves while no significant CSF pulsation artifacts were noted in $3 \mathrm{D}$ bFFE.

The $3 \mathrm{D}$ bFFE sequence was more statistically significantly better than 3D DRIVE for demonstration of the cochlear, superior and inferior vestibular nerves. Table (1). Fig. (1).

Table (1): Comparison of 3D DRIVE and 3D bFFE for assessment of internal auditory canal cranial nerves.

\begin{tabular}{|c|c|c|c|}
\hline & 3D DRIVE & 3D BFFE & $p$ \\
\hline \multicolumn{4}{|c|}{ Facial nerve: } \\
\hline Good & $28(93.3 \%)$ & $30(100 \%)$ & 0.150 \\
\hline Fair & $2(6.7 \%)$ & 0 & \\
\hline \multicolumn{4}{|c|}{ Cochlear nerve: } \\
\hline Good & $26(86.7 \%)$ & $30(100 \%)$ & 0.038 \\
\hline Fair & $4 \quad(13.3 \%)$ & 0 & \\
\hline \multicolumn{4}{|c|}{ Superior vestibular nerve: } \\
\hline Good & $25(83.3 \%)$ & $30(100 \%)$ & 0.019 \\
\hline Fair & $5 \quad(16.7 \%)$ & 0 & \\
\hline \multicolumn{4}{|c|}{ Inferior vestibular nerve: } \\
\hline Good & $25(83.3 \%)$ & $30(100 \%)$ & 0.019 \\
\hline Fair & $5 \quad(16.7 \%)$ & 0 & \\
\hline
\end{tabular}


Table (2): Comparison of 3D DRIVE and 3D bFFE sequences for assessment of the cochlear anatomic structures.
Table (3): Comparison of 3D DRIVE and 3D bFFE for assessment of semicircular canals and vestibule.

\begin{tabular}{|c|c|c|c|c|c|c|c|}
\hline & 3D DRIVE & 3D BFFE & $p$ & & 3D DRIVE & 3D BFFE & $p$ \\
\hline \multirow{2}{*}{$\begin{array}{l}\text { Basal turn: } \\
\text { Good } \\
\text { Fair }\end{array}$} & $27(90 \%)$ & $30(100 \%)$ & \multirow[t]{2}{*}{0.075} & Lateral SCC: & & & \multirow{3}{*}{0.150} \\
\hline & $3(10 \%)$ & & & Good & $30(100 \%)$ & $28(93.3 \%)$ & \\
\hline \multirow{3}{*}{$\begin{array}{l}\text { Middle turn: } \\
\quad \text { Good } \\
\quad \text { Fair }\end{array}$} & & & \multirow{3}{*}{0.150} & Fair & 0 & $2(6.7 \%)$ & \\
\hline & $28(93.3 \%)$ & $30(100 \%)$ & & Posterior SCC: & & & \multirow{4}{*}{0.150} \\
\hline & $2(0.1 \%)$ & & & Good & $30(100 \%)$ & $28(93.3 \%)$ & \\
\hline $\begin{array}{l}\text { Apical turn: } \\
\text { Good }\end{array}$ & $28(93.3 \%)$ & $30(100 \%)$ & \multirow[t]{2}{*}{0.150} & Fair & 0 & $2(6.7 \%)$ & \\
\hline Fair & $2(6.7 \%)$ & 0 & & Superior SCC: & & & \\
\hline \multirow{3}{*}{$\begin{array}{l}\text { Modiolus and spiral } \\
\text { lamina: } \\
\text { Good } \\
\text { Fair }\end{array}$} & & & & Good & $30(100 \%)$ & $28(93.3 \%)$ & \multirow[t]{3}{*}{0.150} \\
\hline & & & \multirow{2}{*}{0.150} & Fair & 0 & $2(6.7 \%)$ & \\
\hline & $\begin{array}{l}28(93.3 \%) \\
2(6.7 \%)\end{array}$ & $\begin{array}{l}30(100 \%) \\
0\end{array}$ & & Vestibule: & & & \\
\hline $\begin{array}{l}\text { Basal turn mean } \\
\text { diameter }\end{array}$ & $5.31 \pm 0.23 \mathrm{~mm}$ & $5.49 \pm 0.29 \mathrm{~mm}$ & 0.067 & $\begin{array}{l}\text { Good } \\
\text { Fair }\end{array}$ & $\begin{array}{l}30(100 \%) \\
0\end{array}$ & $\begin{array}{l}27(90 \%) \\
3(10 \%)\end{array}$ & 0.075 \\
\hline
\end{tabular}
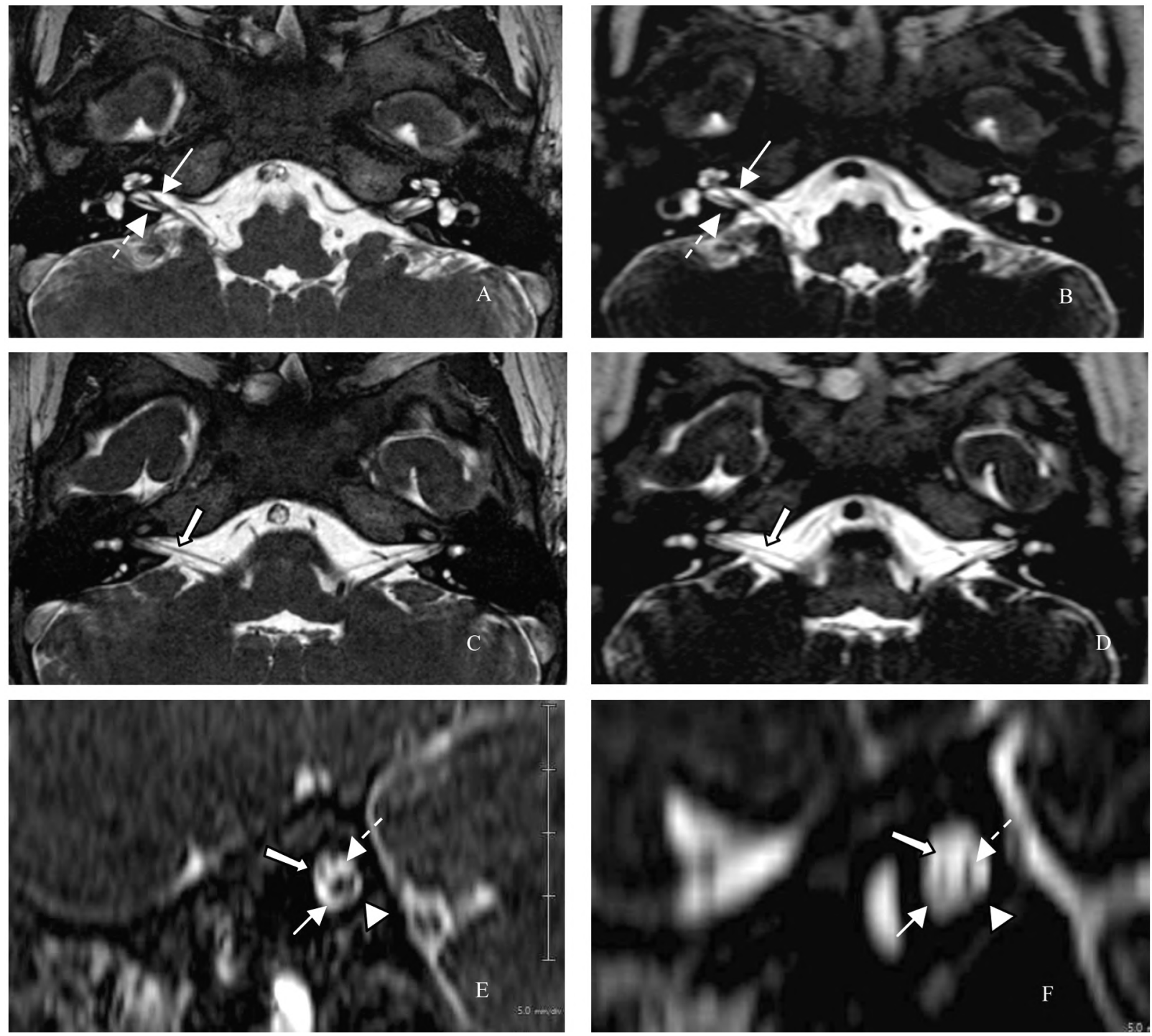

Fig. (1): Axial 3D bFFE (A,C) and 3D DRIVE (B,D) at the level of the cochlear nerve (solid arrow) and vestibular nerve (dashed arrow) (A,B), and at facial nerve (large arrow) level (C,D). Sagittal reconstructed images from 3D bFFE and 3D DRIVE (E, F); the axial and sagittal 3D bFFE images show much better visualization of the cochlear nerves (solid arrow), superior vestibular nerves (dashed arrow), inferior vestibular nerves (arrow head) and facial nerve (large arrow) than in the 3D DRIVE. 
Although no statistically significant difference was noted between the 3D bFFE and 3D DRIVE, yet the 3D bFFE showed a little degree of supremacy over the 3D DRIVE for visualizing the facial nerve as well as the cochlear apical $\&$ middle $\&$

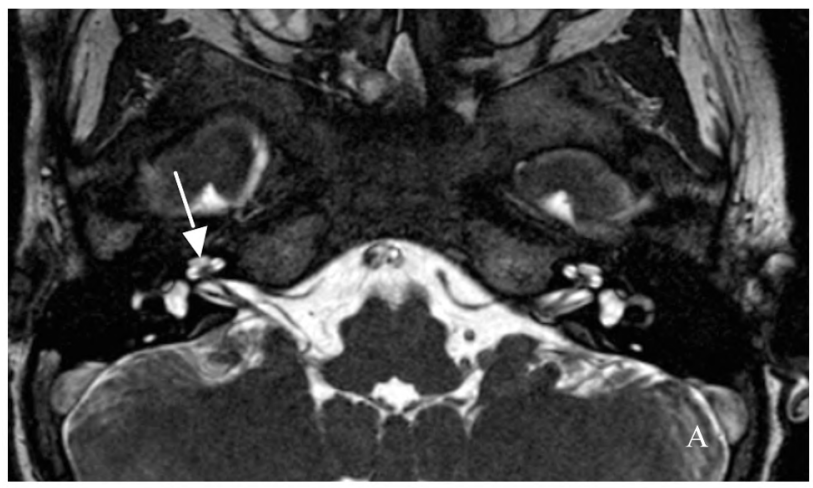

(A)

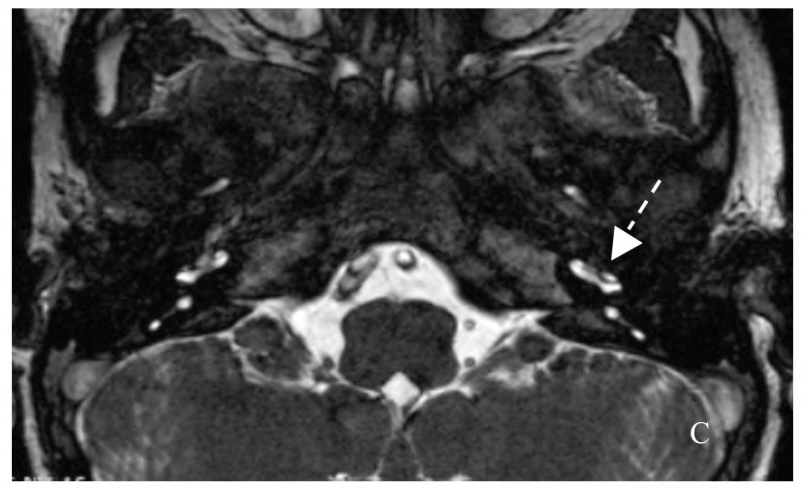

(C)

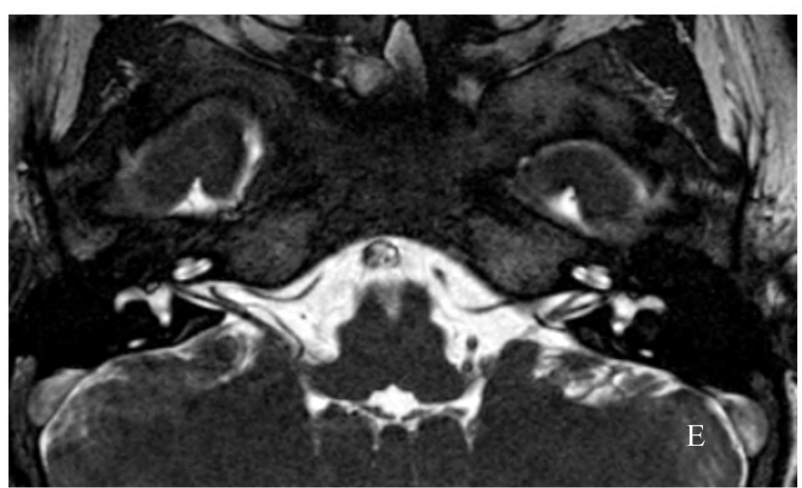

(E) basal turns, modiolus and spiral lamina. Tables $(1,2)$. Figs. $(1,2)$. The 3D DRIVE showed a small supremacy over 3D bFFE for visualization of the three semicircular canals (SCC) and vestibule. Table (3). Fig. (3).

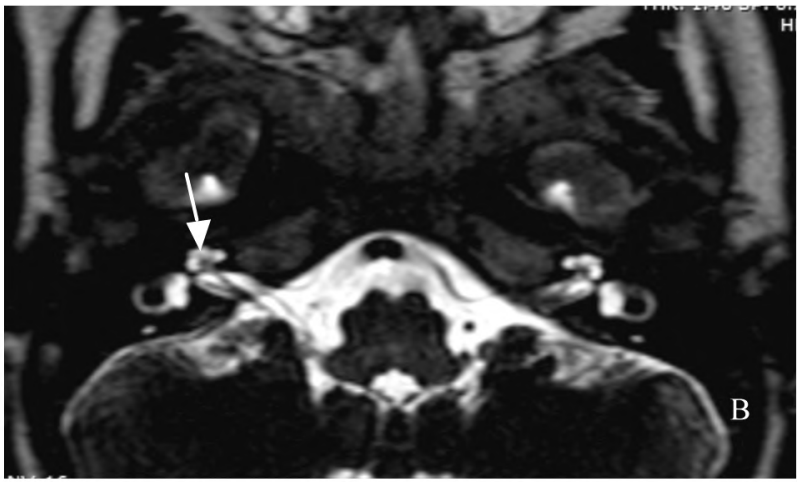

(B)

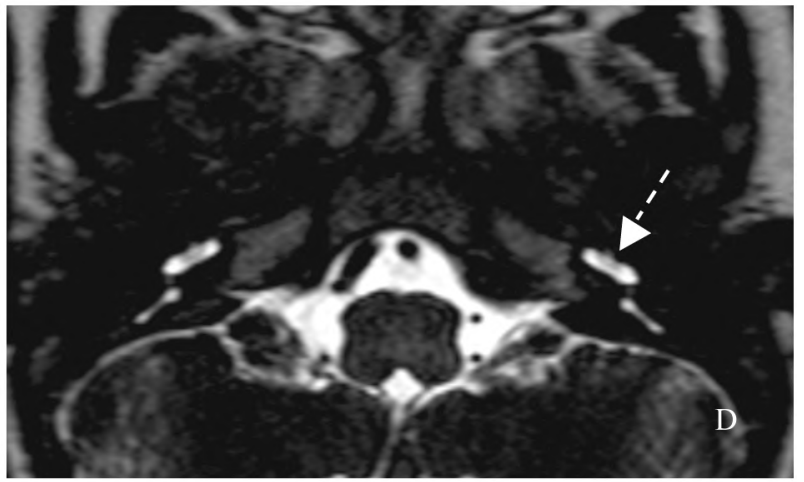

(D)

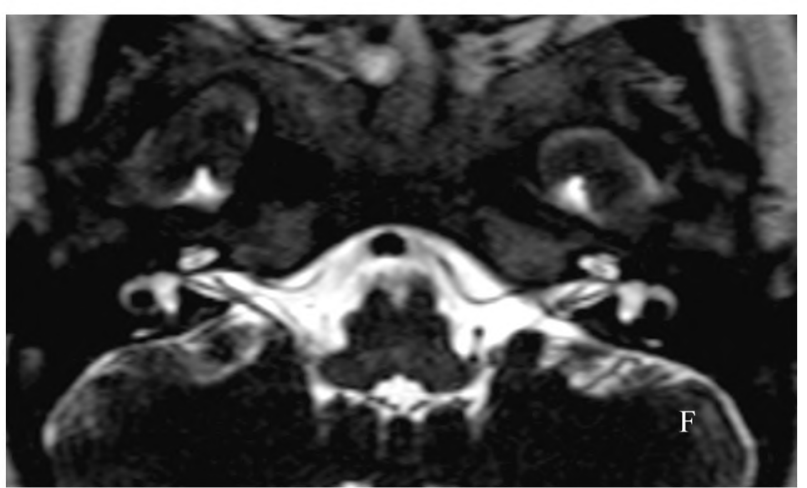

(F)

Fig. (2): Axial 3D bFFE (A,C,E) and 3D DRIVE (B,D,F) at level of the cochlear aperture and modiolus (solid arrow) (A,B), at level of cochlear basal turn (dashed arrow) (C,D), and at level of apical and middle cochlear turn (E,F). The 3D bFFE images show better visualization of the cochlear nerve entry into the cochlea, better visualization of modiolus and spiral lamina, better visualization of cochlear basal, middle and apical turns compared to the 3D DRIVE images. 

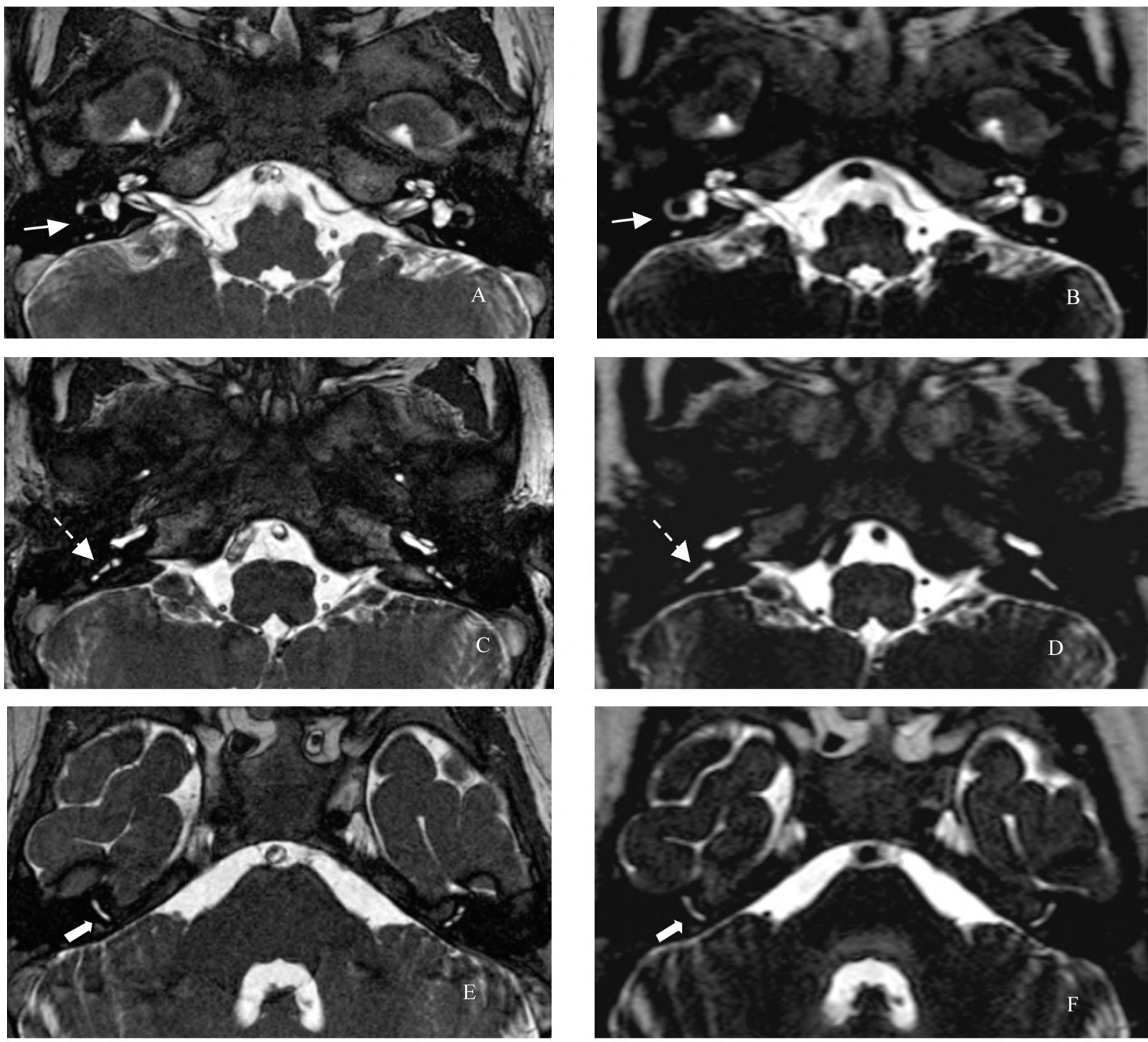

Fig. (3): Axial 3D bFFE (A,C,E) and 3D DRIVE (B,D,F) at level of the lateral semicircular canal (solid arrow) (A,B), at the of the posterior semicircular canal (dashed arrow) (C,D), and at level of the superior semicircular canal (large arrow) (E,F). The 3D bFFE images show multiple discontinuous areas in the semicircular canal which is not seen in the 3D DRIVE.

\section{Discussion}

Visualization of inner ear structures and vestibulocochlear nerve with great accuracy and precision became mandatory in many cases especially in preoperative assessment before cochlear implantation as the prerequisite for the operation include normal cochlear nerve and normal diameter of the basal turn of the cochlea, this means that the inaccurate assessment of these structure will have disastrous effect on the patient [3]. The two techniques most widely used for evaluation of inner ear structures are the 3D DRIVE which is fast recovery fast spin-echo sequence and $3 \mathrm{D}$ bFFE which is fast gradient echo sequence. Both of them can provide a high spatial resolution imaging with high signal to noise ratio and high contrast to noise ratio of the inner ear structures with good cisternographic effect allowing more detailed visualization of the IAC cranial nerves, yet an inherent disadvantage and drawbacks are seen on both of them $[12,13]$

Our study revealed that the $3 \mathrm{D}$ bFFE was generally better than the 3D DRIVE for the demarcation of the IAC cranial nerves, as the 3D bFFE was statistically better than 3D DRIVE for visualization of the cochlear nerve as well as the inferior and superior vestibular nerves within the internal auditory canal and it was slightly better for demonstration of internal auditory canal facial nerve segment, these finding was attributed to the less pulsation and blurring artifacts noted in the 3D bFFE and the better contrast resolution between 
the nerves of internal auditory canal and the surrounding CSF yielding better demarcation of the cranial nerves. Our results were matched with the Tsuchiya et al., [14] and Jung et al., [12] who also reported that the $3 \mathrm{D}$ bFFE was better than $3 \mathrm{D}$ DRIVE for demarcation of vestibulocochlear nerve, yet different results were seen in other studies; lane et al., [1] who compared 3D CISS which is one of FGRE sequence with 3D FRFSE and his study concluded that there was no difference between two sequence in the demarcation of ICA cranial nerves, yet Byun et al., [15] revealed that the 3D DRIVE was better than 3D bFFE for visualization of IAC cranial nerves.

Blurring of image is considered the main disadvantage of the 3D fast spin-echo technique which tends to occur because the echoes are collected in different magnetization states, yet the bFFE sequence uses an entirely balanced gradient in the three orthogonal axes, giving the magnetization chance to reach a steady state [16], so it effectively visualizes the neurovascular structures within the cerebellopontine angle fluid with high contrast and better signal to noise ratio and with less CSF pulsation artifacts [17].

The high sensitivity of 3D bFFE to the magnetic susceptibility is considered the major drawback if 3D bFFE [18] however it may be compensated by the very short TE and the use of broad bandwidth [11].

Our study revealed discontinuity in the three semicircular canals in the 3D bFFE sequence which appear continuous in the 3D DRIVE, similar result was also seen in study conducted by Jung et al., [12] and Byun et al., [15] and this could be explained by the fact that the magnetic susceptibility effect of GRE technique is more apparent in the narrowed structures like the SCC, yielding discontinuity along their course.

Although our results showed that there was no statistically significant difference between 3D bFFE and 3D DRIVE for demarcation of the cochlear turns and the cochlear basal turn mean diameter, yet it revealed that the 3D bFFE was slightly better than 3D DRIVE for demonstration of the cochlear apical, middle and basal turns, this was matched with Lane et al., [1] who revealed that there was no difference between FGRE and FRFSE sequences for delineation of cochlear turns. Opposite result was concluded by Byun et al., [15] who compared 3D bFFE with 3D DRIVE using 3T MRI machine, and his study revealed that the 3D DRIVE was better than the 3D bFFE yet it was not statis- tically significant, the less image quality of 3D bFFE in his study regarding the cochlear turns may be attributed to the banding artifact induced by the strong magnetic susceptibility effect inherent to the GRE technique and as the susceptibility changes increase linearly with field strength, it means that the susceptibility artifact is more problematic at $3 \mathrm{~T}$ and less apparent at $1.5 \mathrm{~T}$, this explained why we did not encounter such problem in our study which was done on $1.5 \mathrm{~T}$ machine.

The cochlear modiolus and spiral lamina was slightly better delineated in 3D bFFE compared to 3D DRIVE, opposite result was concluded by Jung et al., [12] and Byun et al., [15], the discrepancy in this result was attributed to that our study gain the benefit of susceptibility artifact seen in 3D bFFE study which made the modiolus and spiral lamina more capacious, yet it was not significant to affect their visualization.

The 3D bFFE sequence has the advantage of relatively short imaging technique due to its short TR time [13], yet the significant drawback of 3D FSE is its long imaging time, this can be compensated by application of DRIVE technique which has the ability to produce 3D-fast spin echo with relatively short scan time as a DRIVE pulse helps fluids to relax faster, so that the TR can be shortened, and the total scan time decreased by considerable amount [19]. The acquisition times can be also reduced by using the sensitivity encoding (SENSE) which is a parallel imaging, yet the sensitivity encoding technique is more helpful in the FRFSE sequence which naturally requires longer acquisition time than in the bFFE sequence and the use of SENSE factor can decrease the DRIVE examination time by half yet it still has longer examination time than bFFE [12]

Few limitations were seen in our study, first it was dependent upon the subjective evaluation of the cranial nerves and inner ear structures in patient with normal inner ear, so we didn't compare the results of the two sequences in patients with pathological lesions, second it was done on $1.5 \mathrm{~T}$ machine which explained the difference in the results between similar studies. Future studies comparing the 3D DRIVE and 3D bFFE in both $1.5 \mathrm{~T}$ and $3 \mathrm{~T}$ machines as well as incorporating software technique to objectively measures the signal to noise ratio, spatial and contrast resolution of the different imaging techniques will be of value.

\section{Conclusion:}

Both 3D bFFE and 3D DRIVE sequences can provide heavily $\mathrm{T} 2$ weighted MR images of rea- 
sonable quality and both of them show strong and weak imaging points, yet we recommend the use of $3 \mathrm{D}$ bFFE due to its slight supremacy and less imaging time.

\section{References}

1- LANE J.I., WARD H., WITTE R.J., et al.: 3-T imaging of the cochlear nerve and labyrinth in cochlear-implant candidates: 3D fast recovery fast spin-echo versus 3D constructive interference in the steady state techniques. AJNR Am. J. Neuroradiol, 25: 618-622, 2004.

2- SEITZ J., HELD P., FRUND R., et al.: Visualization of the IXth to XIIth cranial nerves using 3-dimensional constructive interference in steady state, 3-dimensional magnetization-prepared rapid gradient echo and T2weighted 2-dimensional turbo spin echo magnetic resonance imaging sequences. J. Neuroimaging, 11: 160-164, 2001.

3- CIFTCI E., ANIK Y., ARSLAN A., et al.: Driven equilibrium (drive) MR imaging of the cranial nerves V-VIII comparison with the T2-weighted 3D TSE sequence. Eur. J. Radiol., 51: 234-240, 2004.

4- UNEL S., YILMAZ M., ALBAYRAM S., et al.: A Radiological Study on the Topographical Relationships between the Vestibular, Cochlear and Facial Nerves. EAJM, 44: 6-12, 2012

5- AYDiN H., ALT1N E., DILLI A., et al.: Evaluation of jugular foramen nerves by using b-FFE, T2-weighted DRIVE, T2-weighted FSE and post-contrast T1-weighted MRI sequences. Diagn. Interv. Radiol., 17: 3-9, 2011.

6- Connor S.E.J. Contemporary imaging of auditory implants. Clin. Radiol., 73 (1): 19-34, 2018.

7- CASSELMAN J.W., KUHWEIDE R., DEIMLING M., et al.: Constructive interference in steady state-3DFT MR imaging of the inner ear and cerebellopontine angle. AJNR Am. J. Neuroradiol., 14: 47-57, 1993.

8- NAGANAWA S., KOSHIKAWA T., FUKATSU H., et al.: MR cisternography of the cerebellopontine angle: comparison of three-dimensional fast asymmetrical spinecho and three dimensional constructive interference in the steady-state sequences. AJNR Am. J. Neuroradiol., 22: 1179-1185, 2001.

9- NAKASHIMA K., MORIKAWA M., ISHIMARU H., et al.: Three-dimensional fast recovery fast spin-echo imaging of the inner ear and the vestibulocochlear nerve. Eur. Radiol., 12: 2776-2780, 2002.

10- SCHMALBROCK P.: Comparison of three-dimensional fast spin echo and gradient echo sequences for highresolution temporal bone imaging. J. Magn. Reson. Imaging, 12: 814-825, 2000.

11- NAKAMURA T., NAGANAWA S., KOSHIKAWA T., et al.: High-spatial-resolution MR cisternography of the cerebellopontine angle in 90 seconds with a zero-fill interpolated fast recovery 3D fast asymmetric spin-echo sequence. AJNR Am. J. Neuroradiol., 23: 1407-1412, 2002.

12- JUNG N.Y., MOON W.J., LEE M.H., et al.: Magnetic resonance cisternography: Comparison between 3dimensional driven equilibrium with sensitivity encoding and 3-dimensional balanced fast-field echo sequences with sensitivity encoding. J. Comput Assist Tomogr., 31: 588-591, 2007.

13- PREIBISCH C., PILATUS U., BUNKE J., et al.: Functional MRI using sensitivity-encoded echo planar imaging (SENSE-EPI). Neuroimage, 19: 412-421, 2003.

14- TSUCHIYA K., AOKI C. and HACHIYA J.: Evaluation of MR cisternography of the cerebellopontine angle using a balanced fast-field echo sequence: Preliminary findings. Eur. Radiol., 14: 239-242, 2004.

15- BYUN J.S., KIM H.J., YIM Y.J., et al.: MR imaging of the internal auditory canal and inner ear at 3T: Comparison between 3D driven equilibrium and 3D balanced fast field echo sequences. Korean J. Radiol., 9 (3): 212-218, 2008.

16- CHEN J.Y., CHOU P.Y., CHEN P.T., et al.: Value of Balanced Fast Field Echo-assisted Three Dimensional Time-of-flight to Diagnose Intracranial Arterial Stenosis. WIMJ, 5 (2): 52-55, 2018.

17- SCHEFFLER K. and LEHNHARDT S.: Principles and applications of balanced SSFP techniques. Eur. Radiol., 13: 2409-2418, 2003.

18- LI T. and MIROWITZ S.A.: Fast T2-weighted MR imaging: Impact of variation in pulse sequence parameters on image quality and artifacts. Magn Reson Imaging, 21: 745-753, 2003.

19- MELHEM E.R., ITOH R. and FOLKERS P.J.: Cervical spine: Three-dimensional fast spin-echo MR imaging improved recovery of longitudinal magnetization with driven equilibrium pulse. Radiology, 218: 283-288, 2001. 


\section{دراسة مقارنة بين تقنية صلى المجال السريع المتوازن ثلاثية الأبعاد

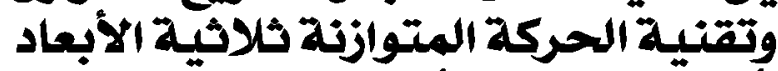

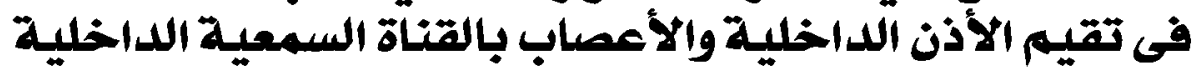

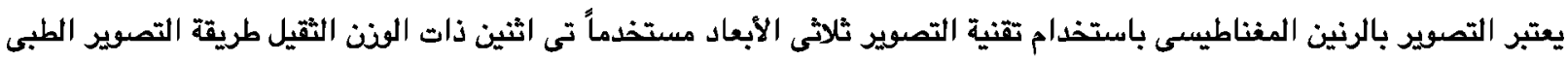

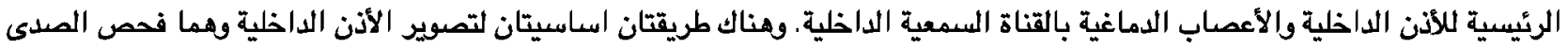

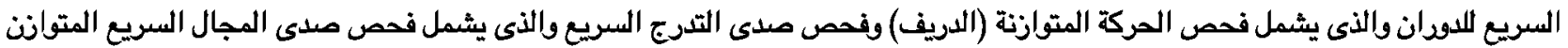
(البفقى).

الهدف: تهدف هذه الدراسة إلى مقارنة جودة التصوير باستخدام طريقة الدريف وطريقة البفىى فى تصوير الأعصاب الدماغية بالقناة السمعية الداخلية وتصوير المكونات الداخلية للأذن الداخلية.

المرضى وطريق البحث: القد تم اجراء فحص الرنين المغناطيسى على خمسة عشر مريض، حيث تم تصوير منطقة الأنن الداخلية باستخدام

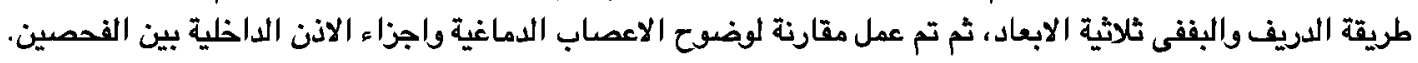

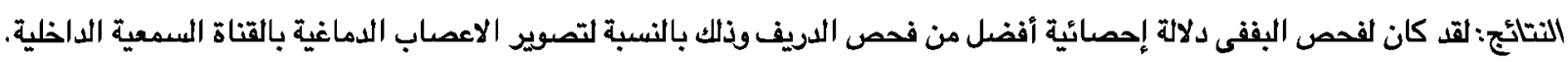

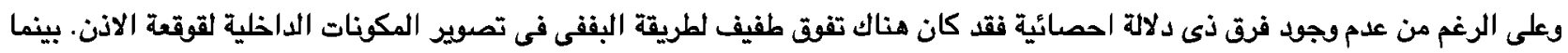

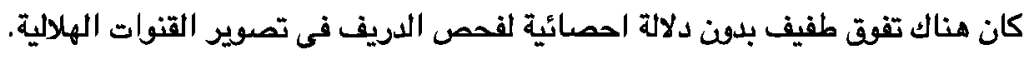

الاستتاج: القد ظهر فحص البففى جقدة تصوير أفضل قليلاً من فحص الدريف بالاضافة الى انه يحتاج الى وقت تصوير أقل من فحص 